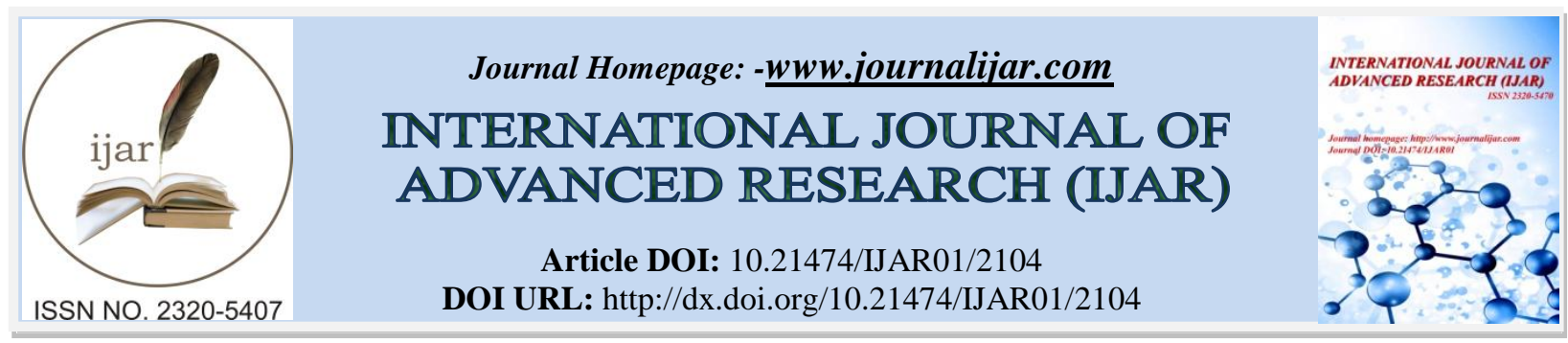

RESEARCH ARTICLE

\title{
EFFECT OF EDUCATION AND PARITY ON THE USE OF CONTRACEPTION IN TAIF REGION.
}

\author{
Farzana Rizwan $^{1}$, Nisreen K Aref ${ }^{2}$, Norah Zafer Alasmari3 and Mashael A Alzahrani ${ }^{3}$. \\ 1. Associate professor / Department of Obstetrics and Gynecology, Faculty of Medicine, Taif University, SA. \\ 2. Assistant professor / Department of Obstetrics and Gynecology, Faculty of Medicine, Taif University, SA. \\ 3. $6^{\text {th }}$ Medical Student, College of medicine, Taif University.
}

\section{Manuscript Info}

Manuscript History

Received: 24 September 2016

Final Accepted: 26 October 2016

Published: November 2016

Key words:-

Contraception, reproductive age, education, parity

\section{Abstract}

Introduction: Saudi women are using contraception for child spacing rather than limiting fertility, especially after having a certain number of children. Effect of education and parity on prevalence of contraceptives use was not studied in this region of Saudi Arabia. Thus, the present study was conducted to identify the effect of education and parity on prevalence of contraceptives use by women of this region.

Research Methodology: A descriptive cross-sectional study was conducted in Obstetrics and Gynecology outpatient clinic in King Abdul Aziz Specialist Hospital, Taif, Saudi Arabia from January to March, 2015. Married women living with spouse, aged 18 to 49 years and having at least one child were invited to participate in the study through convenience sampling method. The data was collected on socio demographic characteristics as well as contraceptive use from all enrolled participants after informed consent. The data was analyzed using SPSS21 statistical software (IBM SPSS Inc., Chicago, IL, USA). Results: Among four hundred and fifty four participants, majority $(52.6 \%)$ were non users of contraceptives. The most common method of contraceptive use was pills (74\%), followed by IUCD (16.7\%), and male condoms $(4.7 \%)$. Significant difference was found in comparison of education between the two groups, where around eighty five percent of contraceptive users had education of secondary level or above compared to only sixty five percent among non-contraceptive users ( $\mathrm{p}$ value $<0.001)$. Moreover, parity also showed significant difference, where slightly more than fifty percent of contraceptive users had parity greater than two, compared to around seventy five percent in noncontraceptive users ( $\mathrm{p}$-value $<0.001$ ).

Conclusion: There is significant increase in using contraception among Saudi women in Taif region in reproductive age group and this intention to use of different contraceptive methods was found associated with the increase level of education and parity.

Copy Right, IJAR, 2016,. All rights reserved.

\section{Introduction:-}

According to World Health Organization (WHO), the prevalence of contraceptive use among a society is one of the determinants of women's health and empowerment in that society. ${ }^{1}$ Some societies are using contraceptives to regulate pregnancies and birth spacing. ${ }^{2}$ Birth spacing has been identified as one of the six essential health 
interventions needed to achieve safe motherhood by the World Health Organization. ${ }^{3}$ Contraceptive use has increased in nearly every country in recent decades. ${ }^{4}$ Among developing countries fertility and contraceptive use have been associated with various markers of socioeconomic status, most important of which is women's education. There is a well-documented link between female education and use of contraception which can play an important role in development of family planning policies in lower income countries. ${ }^{5}$ Saudi Arabia is a country of population who have the desire for large family and high rate of birth in comparison to those in developed countries. However, the overall rapid change in the socio-demographic pattern of the Saudi Arabian community, notably the changes associated with women's education and work could be an important factor in changing fertility beliefs and behaviors about contraception. On account of these transitions Saudi women have more tendencies towards birth spacing and consequently, the use of contraception. ${ }^{6}$ Contraceptive use can have an impact on increased spacing between children, better child care, improvement of children's health and preservation of the mother's health. Therefore when women is educated she will be in a better position for decision-making and it means that educations a key indicator of women's status. By reviewing the literature, it was found that Saudi women were using contraception for child spacing rather than limiting fertility, especially after having a certain number of children. ${ }^{7,8}$ Effect of education and parity on prevalence of contraceptives use was not studied in this region of Saudi Arabia before, so this study was conducted to find the association of education and parity on prevalence of contraception use by women of this region.

\section{Methods:-}

A descriptive cross-sectional study was conducted in Obstetrics and Gynecology outpatient clinic in King Abdul Aziz Specialist Hospital, Taif, Saudi Arabia from January to March, 2015. Married women living with spouse, aged 18 to 49 years and having at least one child were invited to participate in the study through convenience sampling method. Participants with psychiatric illness, speech defects, medical/ surgical illness and not willing to give informed consent were excluded. Prior to enrollment in the study a written informed consent was obtained from all eligible participants. Participation in this study was voluntary and the study participants had the right to withdraw during any stage of the research or not to respond to any one or more questions. Anonymity and confidentiality of the participant's response was maintained throughout the research project. The study was approved by the Institutional Review Board (IRB) of King Abdul Aziz Hospital.

Data was collected using a structured questionnaire. The Questionnaire was developed both in English and Arabic language and was used accordingly based on the language understood by the participants. The questionnaire consisted of two parts; the first part of the questionnaire collected socio-demographic information (i.e. age, education, residence as rural or urban, employment status and parity) of the participants while the second part collected information on contraceptive use.

\section{Data Analysis:-}

Then SPSS 21.0 statistical software (IBM SPSS Inc., Chicago, IL, USA) was used for statistical analyses. The data was entered and validated twice for incorrect entries. Questions with missing responses were excluded from analysis. Descriptive statistics were performed. Qualitative variables (i.e. age categories, residence, education, employment status, parity and contraceptive use) were presented as frequency and percentage. Chi square statistics was used to test an association between contraceptive use with education and parity. For the level of significance, $p$ value $<0.05$ was considered significant.

\section{Results:-}

The questionnaire was distributed to 510 eligible participants. The response rate was around eighty three percent (94.1\%) with four hundred and eighty participants completed the questionnaire. Among those twenty six questionnaires were incomplete or with missing responses which were excluded. Finally, the data of four hundred and fifty four $(\mathrm{n}=454)$ was analyzed.

The table 1 gives details of the socio demographic characteristics of the study participants. Majority (43.2\%) of the participants were in age category 31-40 years, followed age category of 20-30 years (36.3\%). Among the participants, only around forty one percent had education above secondary level. Majority (87.2\%) of the study participants belonged to urban areas. Predominantly, the participants were house wives where only ninety seven participants (21.4\%) were employed. Slightly, less than three quarter of the participants (70.9\%) had parity 1-4. 
Table 1:- Socio Demographic characteristics of the study participants $(\mathrm{N}=454)$

\begin{tabular}{|l|l|}
\hline Socio demographic characteristics & $\mathrm{n}(\%)$ \\
\hline Age categories (years) & \\
\hline$<20$ years & $12(2.6)$ \\
\hline $20-30$ years & $165(36.3)$ \\
\hline $31-40$ years & $196(43.2)$ \\
\hline $41-49$ years & $81(17.8)$ \\
\hline Education level & \\
\hline Uneducated & $25(5.5)$ \\
\hline Primary level & $91(20.0)$ \\
\hline Secondary level & $151(33.3)$ \\
\hline Higher level & $187(41.2)$ \\
\hline Residence & \\
\hline Urban & $396(87.2)$ \\
\hline Rural & $58(12.8)$ \\
\hline Parity & \\
\hline $1-2$ & $167(36.8)$ \\
\hline $3-4$ & $155(34.1)$ \\
\hline $5-6$ & $91(20.0)$ \\
\hline 7 and more & $41(9.0)$ \\
\hline Employment status & \\
\hline Employed & $97(21.4)$ \\
\hline Non employed & $357(78.6)$ \\
\hline
\end{tabular}

Among four hundred and fifty four participants, majority (52.6\%) were non users of contraceptives. Among, two hundred and fifteen participants who affirmed the use of contraceptive, the most common method of contraceptive use was pills (74\%), followed by IUCD (16.7\%), and male condoms (4.7\%). The traditional methods (i.e. rhythm and withdrawal) were less common and practiced by only by less than five percent. Table 2 give details of the contraceptive use.

Table 2:- Use of Contraceptives

\begin{tabular}{|l|l|}
\hline Use of Contraceptives & $\mathrm{n}(\%)$ \\
\hline Contraceptive use & \\
\hline User & $215(47.4)$ \\
\hline Non user & $239(52.6)$ \\
\hline Modern & \\
\hline Pills & $159(74)$ \\
\hline Intrauterine contraceptive device (IUCD) & $36(16.7)$ \\
\hline Male condoms & $10(4.7)$ \\
\hline Traditional & \\
\hline Rhythm & $7(3.3)$ \\
\hline Withdrawal & $3(1.4)$ \\
\hline
\end{tabular}

The table 3 gives details of the comparison of socio demographic characteristics between contraceptive users and non-users. Significant difference was found in age categories, education level and parity. Significantly, greater proportion of participants (45.1\%) in age category (20-30 years) was contraceptive users compared to only $28.5 \%$ in the similar category. No significant difference was found in residence and employment status, although slightly greater proportion of contraceptive users were residing in urban areas and working. Importantly, significant difference was found in comparison of education between the two groups, where around eighty five percent of contraceptive users had education of secondary level or above compared to only sixty five percent among noncontraceptive users. Finally, parity also showed significant difference, where slightly more than fifty percent of contraceptive users had parity greater than two, compared to around seventy five percent in non-contraceptive users. 
Table 3:- Comparison of Socio Demographic characteristics between users and non users of contraceptives

\begin{tabular}{|l|l|l|l|}
\hline Socio demographic characteristics & Users $(\mathrm{n}=215)$ & Non Users(n = 239) & p-value \\
\hline Age categories (years) & & & \\
\hline$<20$ years & $5(2.3)$ & $7(2.9)$ & 0.0026 \\
\hline $20-30$ years & $97(45.1)$ & $68(28.5)$ & \\
\hline $31-40$ years & $83(38.6)$ & $113(47.3)$ & \\
\hline $41-49$ years & $30(14.0)$ & $51(21.3)$ & \\
\hline Education level & & & \\
\hline Uneducated & $4(1.9)$ & $21(8.8)$ & 0.001 \\
\hline Primary level & $29(13.5)$ & $62(25.9)$ & \\
\hline Secondary level & $78(36.3)$ & $73(30.5)$ & \\
\hline Higher level & $104(48.4)$ & $83(34.7)$ & \\
\hline Residence & & & 0.408 \\
\hline Urban & $191(88.8)$ & $205(85.8)$ & \\
\hline Rural & $24(11.2)$ & $34(14.2)$ & \\
\hline Parity & & & 0.001 \\
\hline $1-2$ & $105(48.8)$ & $62(25.9)$ & \\
\hline $3-4$ & $66(30.7)$ & $89(37.2)$ & \\
\hline $5-6$ & $41(19.1)$ & $50(20.9)$ & \\
\hline 7 and more & $3(1.4)$ & $38(15.9)$ & 0.294 \\
\hline Employment status & & & \\
\hline Employed & $51(23.7)$ & $46(19.2)$ & \\
\hline Non employed & $164(76.3)$ & $193(81.8)$ & \\
\hline
\end{tabular}

\section{Discussion:-}

The results of the present study conducted among the married women of reproductive age residing in Taif, Saudi Arabia reported the prevalence of contraceptive use slightly less than fifty percent. Moreover, the study also emphasized that modern methods of contraception (pills, IUCD and male condoms) were more commonly used. Finally, this study suggested that there is a strong relationship between current use of contraception with parity and education of women indecision making about use of contraception.

The present study conducted among the married women of reproductive age residing in Taif, Saudi Arabia reported the prevalence of contraceptive use as around forty seven percent. The reported prevalence of contraceptive use was found far lower than the global rates $(63.1 \%)$ as well as in developed countries (67.4\%) and other countries of Middle East i.e. Syria (58.3\%) and Bahrain (61.8\%). ${ }^{9}$ The result of the present study is slightly higher with the previously conducted study in Saudi Arabia which reported the contraceptive prevalence rate as $40 \%{ }^{3}$

The present study identified that the most common method of contraceptive use was pills followed by IUCD. The findings are consistent with another study conducted in the Qassim region in 2010, which reported that modern contraceptive methods were more used, with pills $(70.2 \%)$, followed by IUCD $(12 \%)$ and male condoms as $(7 \%) .{ }^{3}$ None of the participants reported the use of female sterilization. This can be accounted the participants traditions and Islamic culture that accept only temporary delay of pregnancy and reject permanent sterilization.

There was a strong association between the participants' age and the use of contraceptives. This could suggest that the mother may be satisfied by the number of children she has had and feels that she needs more spacing for preserving her health. This notion is consistent with the results of the indigenous study in a rural area near Riyadh ${ }^{6}$, which reported that parity and current age of the mother were the only significant predictors of birth intervals. The present study highlighted a significant association between current use of contraception with parity and education of women. Women with higher level of education and parity had increased likelihood to adapt to contraceptive use. As in the present study around eighty five percent of contraceptive users had education of secondary level or above compared to only sixty five percent among non-contraceptive users. Previous study from Saudi Arabia also reported that utilization of contraception also increased significantly with the increasing level of education with women with the highest level of education used contraceptives more than twice with odds ratio of 2.7 than the non-educated ones. ${ }^{3} \mathrm{~A}$ recent study from India also reported a significant association between parity and contraceptive use, among the women who had 2 children, $37.2 \%$ were users of contraceptives as compared to $15 \%$ who had more than 2 
children. ${ }^{10}$ Another study from India reported that educating women and their respective husbands about proper use and benefits of modern contraceptives is important to solve the problem of high unmet need for family planning among these tribal women. ${ }^{11}$ A study from Pakistan also reported similar findings, with contraceptive use increased with increasing age of mother, parity and number of living children. ${ }^{12}$ Another study from Pakistan reported that women who had a secondary or higher level of education and three or more children had elevated odds of using contraceptives. ${ }^{13}$ Moreover, more than fifty percent of contraceptive users had parity greater than two, compared to around seventy five percent in non-contraceptive users. The previous study from Saudi Arabia conducted in 2010 also reported that women with higher parity ( 7 and more) were using contraceptives twice as much as those with 1-3 children. ${ }^{3}$ The study conducted in Chennai, India also reported that increased parity is a significant factors for nonusage of contraceptives. ${ }^{10}$ Another study conducted in Cambodia has shown that women who are old, more educated, have higher income and live in urban areas are more likely to use modern contraceptive methods. ${ }^{14}$

\section{Limitations of the Study:-}

The study has few limitations. Firstly, being a cross-sectional survey conducted at single tertiary care setting of Taif region, the findings could not be generalizable. Moreover, only Saudi women who can understand Arabic language were recruited in the study which not be the representative community of the region. Moreover, the participants were recruited through convenience sampling, thus induces the chances of sampling bias. Thus, in future multicenter study will be beneficial in more realistic and precise estimate of association of education and parity with contraceptive use in the Saudi population.

\section{Conclusion:-}

There is significant increase in using contraception among Saudi women in Taif region in reproductive age group (18-49) and this intention to use of different contraceptive methods is associated with the increase level of education and parity. Therefore, increasing awareness about different contraceptive methods, their advantages and limitations among reproductive age women with lower education was deemed essential.

\section{References:-}

1. Mahboub, S. M., Abdelkader, S. M., Al-Muhanna, A., Al-Musallam, F., Al-Ghannam, J., \& Al-Munyif, S. (2013). Attitude towards Contraceptives Use among Saudi Women. International Journal of Healthcare Sciences, 2(2), 331339.

2. Farheen, A. (2013). Ever use of contraceptives among women attending primary health care centers at Abha, Saudi Arabia. International Journal of Current Research and Review, 5(10), 26.

3. Al Sheeha, M. (2010). Awareness and use of contraceptives among Saudi Women attending Primary Care. International Journal of Health Sciences, 4(1), 13-20.

4. Bremner, J., Frost, A., Haub, C., Mather, M., Ringheim, K., \& Zuehlke, E. (2010). World population highlights: Key findings from PRB's 2010 world population data sheet. Population Bulletin, 65(2), 1-12.

5. Saleem, S., \& Bobak, M. (2005). Women's autonomy, education and contraception use in pakistan: A national study. Reproductive Health, 2(1).

6. Al Nahedh, N. N. (1999). The effect of sociodemographic variables on child-spacing in rural Saudi Arabia. Eastern Mediterranean Health Journal, 5(1), 136-140.

7. Salam, A. A. (2013). Nuptiality and fertility in saudi arabia: An appraisal of census data. Middle East Fertility Society Journal, 18(3), 147-153.

8. Al Riyami, A., Afifi, M., \& Mabry, R. M. (2004). Women's autonomy, education and employment in oman and their influence on contraceptive use. Reproductive Health Matters, 12(23), 144-154.

9. World Contraceptive Use. (2007). United Nations, Department of Economic and Social Affairs, Population Division.

10. Anand, A. K., \& Sathiyasekran, W. (2015). Study factors influencing the choice of contraceptive method among eligible couples in a rural population near chennai. Indian Journal of Public Health Research and Development, 6(3), $159-163$.

11. Bibi, S., Memon, A., Memon, Z., \& Bibi, M. (2008). Contraceptive knowledge and practices in two districts of sindh, pakistan: A hospital based study. Journal of the Pakistan Medical Association, 58(5), 254-258.

12. Hamid, S., \& Stephenson, R. (2006). Provider and health facility influences on contraceptive adoption in urban pakistan. International Family Planning Perspectives, 32(2), 71-78.

13. Prusty, R. K. (2014). Use of contraceptives and unmet need for family planning among tribal women in india and selected hilly states. Journal of Health, Population and Nutrition, 32(2), 342-355. 
14. Samandari, G., Speizer, I. S., \& O'Connell, K. (2010). The role of social support and parity on contraceptive use in cambodia. International Family Planning Perspectives, 36(3), 122-131. 